\title{
Housing market cycles - a disequilibrium model and its application to the primary housing market in Warsaw
}

\author{
Hanna Augustyniak*, Jacek Łaszek ${ }^{* *}$, Krzysztof Olszewski ${ }^{* * *}$ \\ and Joanna Waszczuk ${ }^{1}$
}

\begin{abstract}
This paper presents a simple disequilibrium model in the primary housing market, calibrated to the Warsaw market. Our aim is to point out that the primary housing market, due to the long construction process is always in disequilibrium, which has important policy implications. We discuss the last housing cycle and show how a combination of slight demand shocks with short-term rigid supply leads to strong fluctuations of house prices and new construction. The primary market can create a significant distress to the economy, because when house prices rise, this sector attracts capital and workers and is able to generate excessive supply, which finally can lead to the burst of the price bubble. The cyclical character is a permanent feature of the property market and can be explained by the inelasticity of supply. Market participants form price and demand expectations based on past observations. This causes frequent cycles that, under specific conditions, can lead to economic crises. We believe that the model describes the reality of the primary housing market better than equilibrium models do, so it can be useful for central banks and financial supervision institutions in the analysis of the impact of fiscal and monetary policy and regulations on the real estate market.
\end{abstract}

Keywords: Cycles in the housing market, disequilibrium, imbalances, banking sector, banking regulations.

JEL Code: E32, E44, E37, R21, R31.

* Financial Stability Department, Narodowy Bank Polski.

** Warsaw School of Economics and Financial Stability Department, Narodowy Bank Polski.

*** Financial Stability Department, Narodowy Bank Polski. ul. Świętokrzyska 11/21, 00-919

Warszawa, Poland. krzysztof.olszewski@nbp.pl. Corresponding author. 


\section{Introduction}

While modelling the real estate market one usually assumes it to be in equilibrium. However, as a result of a delayed response of supply and changing demand, largely determined by loan availability, the market oscillates around the equilibrium point, fluctuating in time. In this paper we propose a model that accounts for housing needs, which are reflected in a fluctuating housing demand. Supply from the primary market (new construction), which is constant in the short-term, responds with price increases first. Only after a period of time, more new homes are built but prices usually keep growing. Our model allows us to analyze the response of the primary housing market to changes in nominal interest rates or household preferences. We neglect the existing housing stock in this paper and refer to Augustyniak et al. (2014), where we describe the interactions between the primary and secondary housing market in detail. The existing housing stock market hardly faces excessive supply, which is only possible if there is strong migration or if there is very much cheap supply in the primary market. Usually the existing housing stock is owner occupied and changes of its value have a relatively mild effect on the economy 1 . But if we look into the primary market, we observe, for example in the US or Spain, that new construction has created serious problems to the economy and financial stability. New construction is prone to boom and bust cycles, and therefore we analyse the demand and supply of new housing and its cycle.

The analysis of consumer goods requiring a long construction process was described in 1928 by Hanau on the example of a "hog cycle". The investment process and construction of new housing was described, inter alia, by Topel and Rosen (1988) and Augustyniak et al. (2012). Our observations indicate that households purchase not only completed housing, but also real estate development contracts for home construction. When demand is largely unmet, real estate developers sell contracts to provide housing, whose construction has already begun. Typically, contracts are sold after approximately one year from the construction start date. Another two years elapse before the apartment is completed. However, after the housing has been constructed, it ceases to affect the housing market, as the contract had already been sold in the past. It should be noted that real estate developers have some work in progress, which allows them to respond to the market needs relatively quickly ${ }^{2}$. Housing pre-sale contracts are known in the US, Italy, Poland

\footnotetext{
' Positive effects of housing appreciation on consumption are well known in the literature. On the other hand if the housing value falls below the loan amount, the owner will not be willing to sell its house, which might impede his mobility.

${ }^{2}$ The number of building permits obtained by real estate developers usually exceeds the number of actually started constructions. Moreover, not all the constructions started are immediately sold. The real estate developer can extend this process when prices fall and speed it up when prices rise.
} 
as well as in Asia, where this system has had a long history (see Chang and Ward, 1993). Such solutions increase the support elasticity, shorten the cycle and reduce the amplitude of fluctuations. This helps the supply side to respond faster to strongly rising demand, yet, it involves a certain risk. The advantage for clients is that they buy housing at a fixed price. Yet, the buyer bears the risk of the developer's bankruptcy. The developer can continue construction without the need to borrow funds, because the client pays upfront, but he will not be able to increase home prices in the future, along with rising prices or costs.

Figure 1. Commenced housing construction, sold real estate development housing (units, left-hand axis) and real price per square meter (2004 constant prices in PLN, right-hand axis)

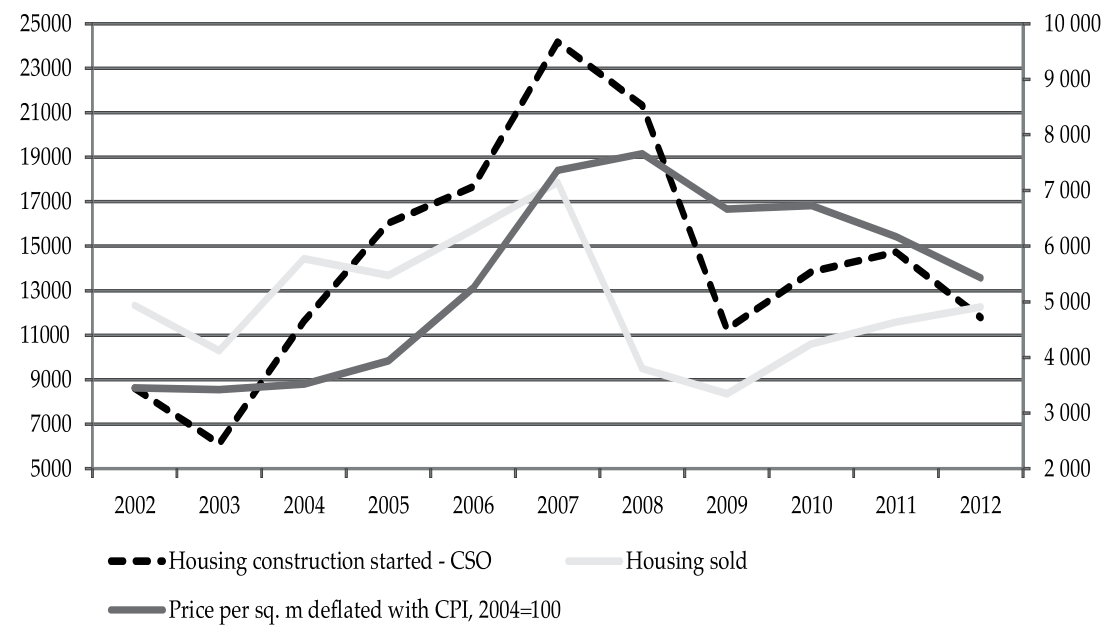

Source: CSO, NBP BaRN, PONT Info, REAS.

Our analysis focuses on Warsaw, the largest housing market in Poland, but given that most of the world experienced a similar housing boom, our analysis can be easily applied to any other market. The available data allow us to capture the last cycle in the Warsaw residential market. It began with stable prices (2002-2004), which then followed an upward trend with rising income, growing supply of credit and declining interest rates (2005-2008). In the subsequent period (2009-2013) prices slowly decreased as a result of economic downturn, oversupply of unsold housing and limited supply of credit. The relationship between loan availability, growing housing demand and rising home prices in the primary market in Poland is discussed in detail in the NBP (2011, 2012a, 2012b) reports. Looking at real prices, deflated by CPI (2004 is the base year), it can be seen that the actual rise in housing transactions and real estate development contracts, in response to growing demand, led also to a rise in transaction prices (see Figure 1). 
When analysing real estate market cycles we need to use a model that replicates the reality as good as possible. One can find very complex models in the literature that describe the housing market. However, in order to solve them, their authors make simplifications and make assumptions which are inconsistent with the reality. In particular, the assumption of the market's rapid search for equilibrium, the assumption about a perfect competition in the market as well as rational behaviour of buyers and producers are problematic. Those simplifications often lead to trivial or even erroneous conclusions. The model presented by us is rather simple and can be replicated on a spread sheet. We show that a fairly simple method allows to analyze imbalances and cycles in the housing market. This requires, of course, relevant data, which, for most of the analysed period, are publicly available on the NBP and CSO website. In our model we go back to the tradition started by Fair (1972) and DiPasquale and Wheaton (1992), who explain the working of the market in a rather simple way.

Our article presents the dis-equilibrium model, analyses cycles and the impact of shocks on the housing market. Chapter 2 presents the model of housing demand. In Chapter 3 we present the model of supply. Chapter 4 presents a regression of aggregate demand and supply as well as price and construction cost changes and Chapter 5 concludes the article.

\section{Housing demand}

In this section we present a simple demand model. While the housing market consists of new construction and sales from the existing stock, it is well known that only the supply of new construction can adjust to a credit fuelled housing demand boom in the short and medium run (Augustyniak et al. 2014). The supply from the existing housing stock is rigid in the short and medium run, thus any excessive demand translates very quickly into excessive demand for new construction. Therefore, we focus on the primary market only and we assume that households finance home purchase with a loan. The cost incurred in a particular period by the household is the loan repayment. Burnham (1972) quotes a Fed survey, according to which credit supply determines housing construction. Currently, we see that housing demand both in Poland and across the world is driven by credit supply (see NBP, 2012a,b). Moreover, demand is affected by consumer preferences as regards the consumption of other goods $C$ and housing services. Like Bajari et al. (2013) we include the imputed rent $\mathrm{kpH}$ in the utility function. It results from the size of the apartment $\mathrm{H}$, its price $\mathrm{p}$ and the parameter $\mathrm{k}$, which reflects the monetary value of the stream of housing services. The utility is described by a CES function, where $\theta$ is the share of utility resulting from consumption, whereas the parameter $\mu$ denotes the elasticity of substitution between consumption and housing, $\varepsilon=1 /(1-\mu)$. Accounting for appreciation, 
$A=\frac{p_{t}}{p_{t-1}}$, we take into consideration consumer expectations about future housing prices (see Dunsky and Follain, 1997, Sommervoll et al., 2010 or Lambertini et al., 2012). Such a specification of the utility function takes into account the fact that housing is bought for consumption as well as for investment purposes (see Henderson and Ioannides, 1983 and Laszek, 2013). It also reflects the fact that households extrapolate past prices and are prone to herding behaviour (see Salzman and Zwinkels, 2013). The utility of household is described by the following equation:

$$
\left.U(C, H)=\left(\theta C^{\mu}+(1-\theta) A^{\gamma} k p H\right)^{\mu}\right)^{\frac{1}{\mu}}
$$

The consumer divides his income between the loan repayment and consumption of other goods. It is very important to remember that not only house prices but also income rises in the real world. If both increase at the same pace, the consumption of housing, measured in square meters should not change. Moreover, after a housing boom relative house prices tend to decline, as the analysis in NBP (2013) shows.

The income allocation problem is solved by taking into account the budget constraint $b=r p H+C$ ( $r$ - loan constant based on fixed loan instalments, $p$ - price per square meter of housing), which gives us the optimal choice of the size of housing and consumption of other goods in each period.

$$
\theta C^{\mu-1} r p=(1-\theta) A^{\gamma}(k p)^{\mu} H^{\mu-1}
$$

By combining this equation with the budget constraint we get the optimum allocation of funds between consumption of housing services and consumption of other goods.

$$
\begin{aligned}
C^{*} & =\frac{b}{1+r p\left(\frac{\theta}{1-\theta} \frac{r p}{A^{\gamma}(k p)^{\mu}}\right)^{\frac{1}{\mu-1}}} \\
H^{*} & =\frac{b}{r p+\left(\frac{1-\theta}{\theta} \frac{A^{\gamma}(k p)^{\mu}}{r p}\right)^{\frac{1}{\mu-1}}}
\end{aligned}
$$

Lin and Lin (1999) argue that income elasticity of demand is approx. 1, consequently, income growth should lead to a similar increase in housing demand. The household is not limited by the budget only, but also by the loan availability and supervisory regulations. The bank calculates the loan availability based on household's income, nominal interest rate and prudential regulations, which determine, among other things, the longest possible period of loan repayment (the longer the maturity 
of the loan, the lower the loan constant and the higher the household loan). When buying an apartment, households usually look at the current market situation and credit granting criteria, neglecting potential changes in interest rates or fluctuations in exchange rates, if they had taken out a foreign currency denominated loan.

In order to curb excessive debt and reduce the risk to the financial system, restrictions are imposed concerning the part of consumer's income which can be spend on the debt repayment (DTI - debt to income ratio) as well as restrictions on the loan to value ratio (LTV) or the down-payment (see Stein 1995, Rubaszek, 2012). For the ease of the analysis, we have considered DTI limits only, so that the household can devote only a part of their income $x \in(0.1)$ to repay the loan, and the monthly instalment payment is maximum $b_{H}$, whereas:

$$
b_{H}=x b \leq b
$$

In this situation, the choice of the size of housing will not always be the optimum allocation of funds between $C^{*}$ and $H^{*}$, but:

$$
\begin{aligned}
& H= \begin{cases}H^{*}, r & p H^{*} \leqslant x b \\
\frac{x b}{r p}, r & p H^{*}>x b\end{cases} \\
& C=\left\{\begin{array}{cc}
C^{*}, r & p H^{*} \leqslant x b \\
(1-x) b, & r p H^{*}>x b
\end{array}\right.
\end{aligned}
$$

Prudential limitations may result in the household's inability to consume a sufficiently large apartment. On the contrary, the household will be forced to consume more other goods than it needs. Figure 2 shows the consumers choice in the case of a normal budget (point A) and a budget limited by prudential restrictions (point B).

\section{Figure 2. Consumer's choice without budget constraints (left-hand panel) and with budget constraints (right-hand panel)}
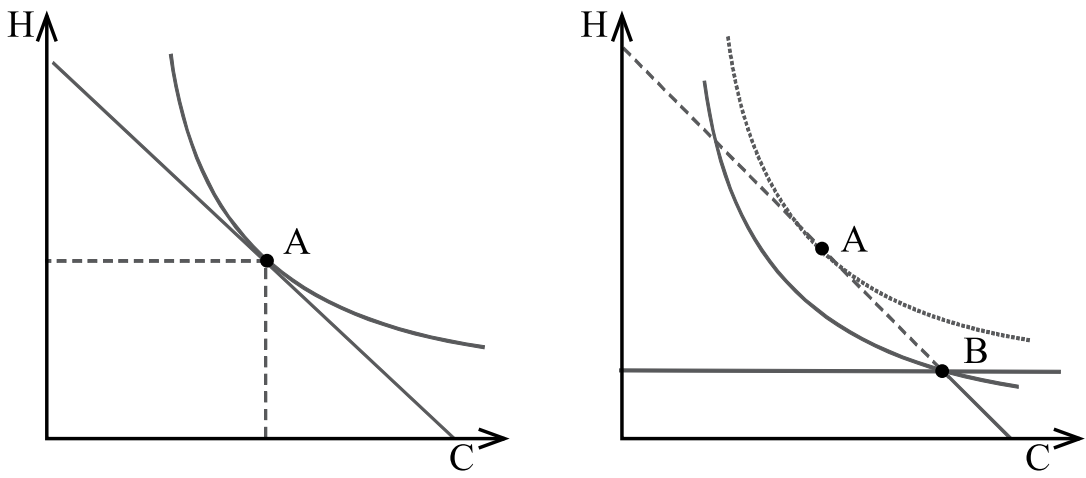
If prudential requirements are restrictive (the household would like to borrow a higher loan than it can), even a slight easing may trigger strong fluctuations in housing demand. Typically, the household is willing to give up some consumption of other goods only to buy more housing. This explains why the availability of foreign currency denominated loans caused a boom in housing demand in Poland.

In order to provide a more thorough explanation of the price bubble, we should present the response of demand to price increases based on a graphical analysis. With the classical utility function, when housing is considered as consumption only, rising prices would lead to a decline in residential consumption from point 1 to point 2 (see Figure 3, left-hand panel). However, as housing is seen as both a consumption good and an investment good, the housing appreciation causes a significant shift of the utility curve. As a result, amidst rising prices housing becomes even a more desirable asset and the buyer will choose the allocation described in point 3 of the left-hand panel of Figure 3. He will decide to sacrifice even a significant part of consumption of other goods, to buy more housing than he would buy at the former, lower price.

\section{Figure 3. Consumer's choice amidst higher prices (left-hand panel) and an additional increase in income and moreover, interest rate cuts (right-hand panel)}
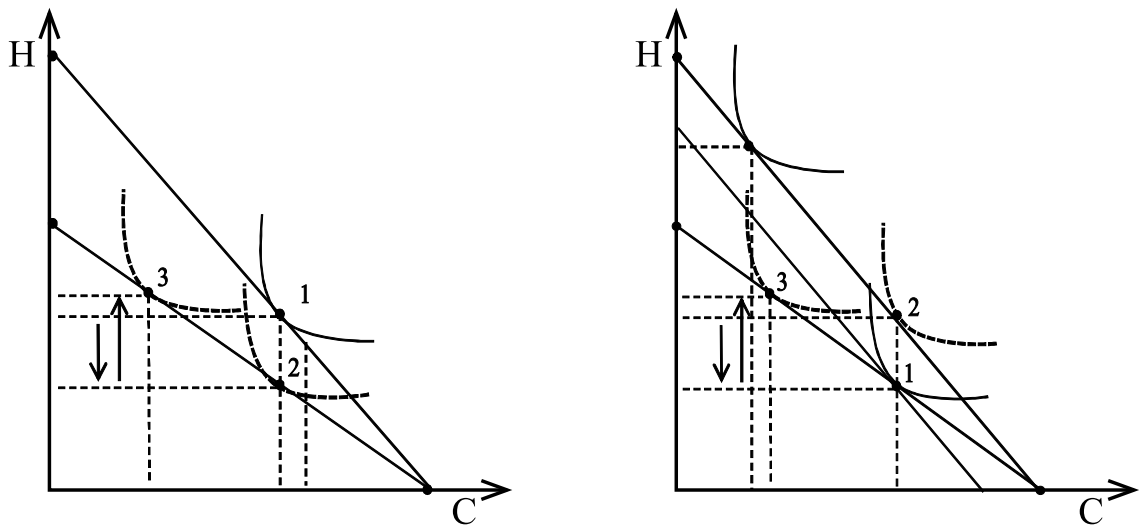

It should be added that prices increased amidst rising incomes and considerable cuts in interest rates. The right-hand panel of figure 3 shows that, in the first place, as a result of rising income the budget line shifts to the right from point 1 to point 2 , thus, the consumer can buy more housing and other goods. Yet, prices rise, so as previously explained, he will choose point 3 . However, a significant decline in interest rates means that the price increase is, in budgetary terms, almost entirely offset, so the budget curve returns to its position before the price increase, and the buyer finally chooses point 4 . The analysis presented in NBP (2013) shows that during the price boom, the loan availability calculated per square meter of housing 
was on the rise which allowed households to purchase increasingly bigger housing. Only a combination of changes in prices, income and interest rates makes it possible to explain a seemingly irrational behaviour of buyers who amidst rising prices expressed demand for increasingly bigger housing. In the aggregate, this translated into a growing demand for housing.

It is worth noting that in terms of the credit boom, households are able to exceed their budget by taking Ponzi loans. From the perspective of a household's individual decision this can be reasonable, as it optimizes its inter-temporal consumption and will repay the excessive debt in the subsequent period through capital gains on housing. This situation was not observed in the Polish market, thus we do not analyse this variant.

\subsection{Calibration of the demand model and analysis of the impact of interest rates on demand}

The housing demand model was calibrated to reflect the actual rise in demand and prices in the Warsaw housing market in the years 2002-2013. When calibrating the model presented in the previous section, we have chosen parameters $\theta, \mu \mathrm{k}$ that are very close to the values proposed by Bajari et al. (2013) for the US $(\theta=0.77, \mu$ $=1.32, \mathrm{k}=0.075)$. We calibrated the model in such a way that it fits the Warsaw housing market as good as possible. We used the same parameter to calculate the substitution elasticity $\mu=1.32$, but modified the importance of consumption in the utility function to $\theta=0.63$. The smaller parameter $\theta$ reflects a stronger desire to own housing. The parameter $\mathrm{k}$, necessary to calculate the imputed rent, was calculated as the average of the actual rental data and transaction prices (from the NBP BaRN database) and amounts to 0.065 . Moreover, we choose the parameter, which determines the strength with which buyers react to housing appreciation as $\gamma=0.5$. As the household budget we take the twofold value of the average net wage in the enterprise sector in a particular year. In total, the model replicates the last demand cycle in the primary housing market in Warsaw well, as shown in Figure 4.

The demand for square meters of housing was calculated as follows: the model demand for one square meter of housing of an average household is multiplied by 13000 - the average number of homes sold during the analysed period, and finally scaled down (by 10000 ) in order to harmonize the scale. To calculate the total area of actually sold housing, the number of apartments sold by real estate developers was multiplied by their average size of 58 square meters, and then the score was scaled down (by 10 000). The loan constant was scaled up by 10 .

Along with a strong decline in the weighted interest rate ${ }^{3}$, a rise was observed in housing demand. Growth in the model demand largely exceeded growth in ac-

${ }^{3}$ The interest rate is weighted with the currency structure of housing loans. 
tual transactions, which was driven by two reasons. At the beginning of the boom, real estate developers were unable to generate a sufficient number of contracts for housing construction. They put new contracts on the market with one year's delay. Although demand slowed down in the later phase of the cycle, real estate developers sold a lot of contracts - meeting the needs of clients who had expressed their demand a year ago. Moreover, growing income and declining interest rates failed to directly translate into bank lending, which began to pick up with some delay.

The demand model allows us to analyse household behaviour in the primary housing market in the boom period. Although the price of a square meter of housing began to increase rapidly, demand continued to grow. This was driven by three major factors: falling interest rates (due to lower FX interest rates), growing income and expectations of further strong appreciation of transaction prices. This overlaps with the desire to own housing (see Augustyniak et al. 2014) and banks' very lenient lending criteria. A longer crediting period, despite the price growth and a slight increase in the average weighted interest rate was a factor behind rising demand. In this way, the loan instalment remained at a low level for a relatively long time. However, if banks had refused to lend for longer periods much earlier, demand would have probably been lower. Figure 4 shows the development in housing demand, under the assumption that both foreign currency denominated and PLN mortgage loans were granted (left-hand panel) or under the assumption that only PLN mortgage loans were granted (right-hand panel).

\section{Figure 4. Housing demand, home prices, interest rates and the number of purchased housing units (left-hand panel- under the assumption that both PLN and foreign currency denominated mortgages were granted, right-hand panel- under the assumption that only PLN mortgages were granted)}
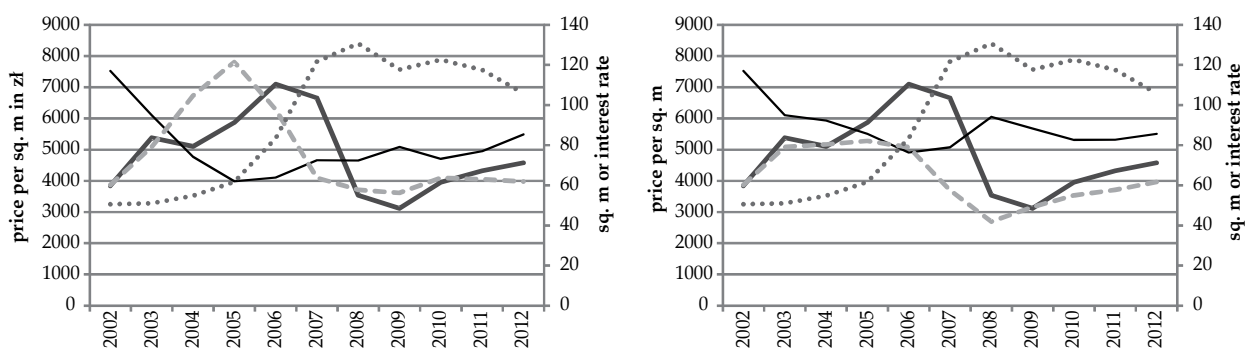

...P $(\mathrm{L})=-$ Demand (R) - H sold (R) — interest rate * 1000 (R)

...P P (L) - - Demand (R) - H sold (R) — interest rate * $1000(\mathrm{R})$

Source: CSO, NBP BaRN, PONT Info, REAS.

The presented model is a partial equilibrium model in which we assume that prices were fixed by real estate developers, and households chose the size of housing only. In fact, reduced demand, resulting from rising interest rates in the absence 
of foreign currency mortgages should not lead to such a strong price increases (see Figure 4, right-hand panel). It is worth noting that the panel analysis presented at NBP (2013) suggests that real estate developers were quick to raise prices during the boom, yet reluctant to cut them down during demand slump.

\section{Supply of real estate developer housing}

As discussed in the introduction, we focus on the supply of new housing. Housing supply in the secondary market is rather stable in the short and medium run, as it is the result of the willingness of the owner to sell his existing asset. Contrary, housing developers can increase production in the medium-run excessively, as they buy new development land, increase the number of workers and also can sell, besides completed housing, pre-sale contracts. Rising prices attract capital to this market, but the long construction process makes the investment risky - the investor hopes to sell the house for a price that exceeds the construction costs.

Although the price elasticity of housing was already analysed in 1960 by Muth for the United States, the supply side was given relatively little attention in the literature ${ }^{4}$. One of the more extensive publications on this subject is the article by DiPasquale (1999). While analysing housing supply, we must take into account the situation in the local real estate markets. Stover (1986) pointed out that the aggregation of data from individual, distant cities leads to significant errors in the estimation of the price elasticity of housing supply. A detailed analysis of the real estate development sector, as well as the profit and cost accounting may be found in Augustyniak et al. (2012), here we focus on the supply curve only ${ }^{5}$.

The short-term supply of developer housing is rigid, because it usually takes around 4 years from the start to the completion of construction. Supply becomes more flexible in the medium term as real estate developers sell contracts, if this is permitted by the law and approved by market participants. Thus, real estate developers put onto the market contracts for home construction, which has only just begun (see Augustyniak et al., 2012) and the whole project will take two more years to complete. During the price boom, the sale of construction contracts began even

\footnotetext{
${ }^{4}$ The modelling of housing supply causes many problems, including analytical ones. Epple, Gordon and Sieg (2010) estimated the home production function based on the price of land. The main problem was that housing consists of attributes that are difficult to valuate objectively, separately, qualitatively or quantitatively (e.g. quality of housing). It should also be noted that housing features are the result of complex decisions made by real estate developers and home owners (see DiPasquale, 1999). In the case of Poland, the problem is also to gain access to full and accurate data series.

${ }^{5}$ The price elasticity of supply is explained theoretically by Levin and Pryce (2009) and estimated for different countries by Phang, Kim and Watcher (2010) and by Sanchez and Johansson (2011).
} 
earlier and the so-called "holes in the ground" were bought. Then, after a period of 3-4 years, completed apartments were delivered to the buyer.

Basing on the relationship between the cost of production and the supply curve of real estate developers, we know that in the medium term the real estate development sector is able to build more housing units at a higher cost. The cost curve will be located close to the marginal cost curve. According to our observations, the mid-term curve of real estate developers' supply may differ significantly from the cost curve, as developers plan future investment based on current prices. They erroneously underestimate the rise in production costs, driven by growing demand and respond only to nominal changes in home prices (see NBP 2013 for more empirical details).

In the medium term, the capital inflow to the residential construction sector pushes the cost of capital down to the level of the minimum average cost (longterm cost). As a result, the supply curve will become even more flexible, as new real estate development companies will enter the market, while the existing ones will increase their production. However, if supply rises too much, the average cost will rise as a result of the negative scale effects (infrastructure, costs of transport, materials, land, etc.).

Moreover, real estate developers often fund their operations using financial leverage, which changes their profitability indicators, as increased production financed in this way offsets the growing unit costs. In some countries, it is possible to finance construction with buyers' pre-payments, enabling developers to save the equivalent of interest they would have to pay on the loan, thus increasing the return on investment. Therefore, due to higher prices, the supply of development contracts may be more flexible in the short-term than suggested by marginal costs.

In the long term, supply of housing will be more flexible thanks to a wider range of possibilities of increasing production. The whole economy will be a subject to structural adjustments aimed at adjusting the supply of housing to meet the society's needs 6 .

\subsection{Real and virtual supply curve}

As in most productive sectors, the supply curve is affected by marginal costs and the price. Firms involved in home construction have generally in place similar, standardized construction methods, so that the aggregate supply curve is the sum

\footnotetext{
${ }^{6}$ It is worth noting that the economy may be subject to erroneous, socially expensive and excessive adjustments made to match new housing supply with demand. We have observed this recently, for example in Spain. Too many factors of production (capital and human resources) were transferred to the real-estate development sector, which generated huge costs: a high vacancy rate and mismatches in the labour market.
} 
of supply curves of individual real estate developers. We can determine two supply curves: the virtual and the real one.

The virtual supply curve $(\mathrm{V})$ is the result of real estate developer's calculation of future return on investment. This calculation is an estimate based on current housing prices, cost of materials and labour. In contrast to a manufacturing firm, which has a fixed capital stock and an optimal production level above which costs rise substantially, the real estate developer relies on outsourcing of construction services and buys a lot of production factors in small batches. For this reason, the individual cost curve is flat and rises with a considerable delay (see Figure 4, lefthand panel). The real estate developer usually operates as a holding, which allows it to create a special purpose vehicle to start new investment projects.

Furthermore, the number of housing units in a particular location can be adjusted to meet the current market needs. Its supply is limited by the access to capital generated by the stock and bonds market and by loans. We should also mention another restriction in the form of a limited number of qualified people who can conduct the construction process and the availability of production factors. Consequently, real estate developers supply curve (S) will be less inclined. It will move to the left, if the real estate developer expects the cost of land, materials and labour to increase or the diseconomy of scale starts to emerge.

Furthermore, the real estate developer can continue a project that was already started and then stopped, should demand increase. In this case, the supply curve of the developer is virtual and subjective as it is based solely on self-estimates and usually does not take into account the behaviour of the competition.

\section{Figure 5. The virtual and actual supply curve (left-hand panel) and changes in the market in response to rising demand (right-hand panel)}
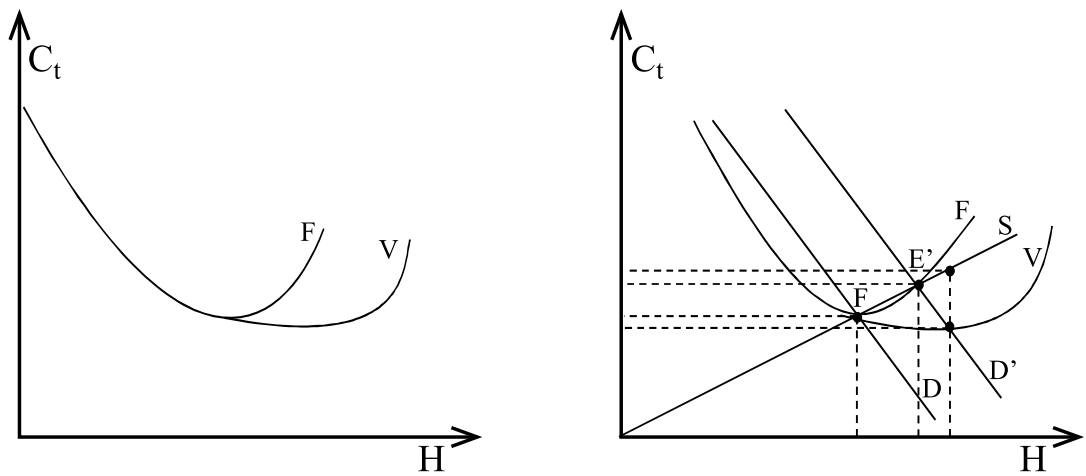

The real supply curve (F) of the entire development sector reflects the actual changes in investment profitability, taking into account diseconomies of scale and increasing costs of production factors, when production reaches too high levels. 
For example, real estate developers will buy less attractive plots of land and will have to adapt them to meet the actual needs or will have to pay more for work and materials. This gives a curve that shows how flexible the response of demand to housing prices is. However, its importance at the planning stage seems to be limited to the individual developer. It will play a major role in the final phase of the project and will determine the number of housing units that are currently being constructed.

If housing prices are stable, growing costs mean that profit margins are lower and, consequently, the expected future profits decline and the virtual supply curve goes up. This results in the suspension of new investments, slowing construction of the existing real estate investments, or even abandonment of the current projects. The virtual and the actual supply curve is shown in the left-hand panel of Figure 5. Rising demand for housing, as shown in the right-hand panel of Figure 4, as a shift in the demand curve to the right (from D to D'), will urge real estate developers to increase housing production. As a result of rising factor prices and the negative scale effects (average costs of production factors begin to grow), the real cost of production of such a large number of dwellings is higher (see curve F) and exceeds the price that consumers are ready to pay. This, in turn, creates a surplus in the housing market. We would like to mention that housing developers have tools to cover excessive costs, as they apply price discrimination during the selling process. As described in Laszek and Olszewski (2014), they offer each housing unit to every buyer at his own reservation price, thus obtain a higher profit than they would obtain under perfect competition.

\section{Aggregate demand and supply estimation}

In this last chapter we investigate empirically the aggregate demand supply and price adjustment process in the primary housing market. Because the annual time series are rather short, we use quarterly data ${ }^{7}$. As the quarterly data shows seasonality and also is more prone to short-term shocks that we do not model here, we use the moving average over four quarters. We base on the previously described model and the housing stock adjustment literature (see Mayer and Sommervoll, 2000 and Steiner, 2010). In aggregate terms there is an equilibrium housing stock level, corresponding to a specific price level. If, for some reason, the demand for the housing stock increases, there is a mismatch between demand and supply and prices rise.

${ }^{7}$ The data on house prices origins from the NBP BaRN data base, data on house sales and housing put on the market comes from REAS, while the construction costs are based on Sekocenbud data. The income data comes from the CSO, while data on interest rates comes from NBP. Data on supply, demand, prices and costs as income is in logs. 
As shocks are a permanent feature, the market is never in pure equilibrium, but it may be very close to it. Following Mayer and Sommervoll (2000), we regress the log-levels of housing demand and supply in a given period on price changes and also explain the price and construction changes by the mismatch between demand and supply. Taking into account the previously described model of individual demand for housing space $\mathrm{H}_{\mathrm{t}}$, we proceed to the aggregate demand $H D_{t}$ for housing units. The aggregate demand in log terms can be described by equation 1 .

$$
H D_{t}=\alpha_{1}+\alpha_{2} P_{t}+\alpha_{3} D\left(P_{t}\right)+\alpha_{4} \text { Intrate }_{t}+\alpha_{5} \text { Income }_{t}+\varepsilon_{t}
$$

Here $P_{t}$ is the $\log$ house price, $D\left(P_{t}\right)$ is the growth rate of the house price. The interest rate $\left(\right.$ Intrate $\left._{t}\right)$ and the income in log terms $\left(\right.$ Income $\left._{t}\right)$ are included to capture the development of the economy. The empirical analysis (see table 1 below) confirms that in aggregate terms housing demand depends positively on the income, while it declines with price or interest rate increases. Moreover, the housing demand increases when prices are on the rise, which confirms the herding or speculative behaviour of home buyers in the primary market. We want to point out that if price increases at the same time as income, both effects annihilate each other. In relative terms, housing measured in units of income is as expensive as it was before the price increase (see also NBP (2013b) for data on other cities in Poland).

The next step is the regression of the aggregate housing supply in the primary market. Again in line with theory we observe that developers react with a lag of one year to price increases, which is captured by $D\left(P_{t-4}\right)$. If prices rise, developers start new construction projects, which they put with a one year lag on the market. Increasing construction costs, captured by $D\left(P C_{t-4}\right)$, decrease their will to start new projects as well as increasing interest rates (denoted Intratet) do. The higher the interest rate is, the more costly is a loan or the higher are the opportunity costs of investing in housing construction. Finally, given the high fixed costs, the developer produces a certain amount of housing, irrespective of the current prices and construction costs. We call this production autonomous (see also Augustyniak et al. 2012).

$$
H S_{t}=\beta_{1}+\beta_{2} D\left(P_{t-4}\right)+\beta_{3} D\left(P C_{t-4}\right)+\beta_{4} \text { Intrate }_{t}+\varepsilon_{t}
$$

The price setting behaviour of the real estate developer is captured by equation 3. First, it turned out that the house price depends strongly on its past level, thus also the current price growth rate $D\left(P_{t}\right)$ depends on its past growth rate $D\left(P_{t-1}\right)$. As the literature on housing cycles shows (see for example Bracke, 2013), there are long periods of price growth and even longer periods of price decline. The developer adjusts the price also to the mismatch between current demand and supply 
(denoted $H S_{t-1}-H D_{t-1}$ ), that is under excessive demand he increases the price (see Tse Ho and Ganesan, 1999).

$$
D\left(P_{t}\right)=\vartheta_{1}+\vartheta_{2} D\left(P_{t-1}\right)+\vartheta_{3}\left(H S_{t-1}-H D_{t-1}\right)+\varepsilon_{t}
$$

We tested whether there is asymmetry in the price adjustment and found that the price increase in response to excessive demand is as strong as the price decline in response to excessive supply. In the case of oversupply, the developer lowers his price expectations slowly, hoping to find a buyer who is willing to pay the price. This has been observed in the Polish real estate market but also in other international markets in the recent years. Even though a fast price decline would allow the market to clear and reach the equilibrium faster, developers are not willing to lower prices too fast. Typically, developers have price expectations and are ready to wait for a client who is willing to pay their price ${ }^{8}$. Also when the construction is financed with a loan, the loan agreement may prevent the developer from lowering prices below a certain threshold. The buyer can negotiate the price, yet has a small amount of information and little bargaining power'. In consequence, the price remains high and even though there is excessive supply, other developers continue to deliver housing to the market.

The last important factor which affects housing construction are construction costs, which we estimate in equation 4 . We observe that construction costs, similar to house prices, tend to depend strongly on their past realization. Moreover, increases in supply require more input goods and rise production costs.

$$
P C_{t}=\rho_{1}+\rho_{2} D\left(P C_{t-1}\right)+\rho_{3}\left(H S_{t-1}\right)+\varepsilon_{t}
$$

We estimate each equation separately using the OLS regression, correcting for heteroskedasticity and autocorrelation. The estimation is run on quarterly data, and due to the limited data length the regression 1 covers the period 2004Q2-2013Q4, regression 2 the period 2005Q1-2013Q4, regression 3 the period 2008Q1-2013Q4 and regression 4 the period 2004Q3-2013Q4.

${ }^{8}$ Compare the offers presented in Figure 4 in NBP (2013).

${ }^{9}$ There is a strong asymmetry of information, the developer can put a smaller number of housing units on the market to create the appearance that housing is a rare good. The housing developer has also marketing tools to convince the client that housing is worth as much as expected by the developer. 
Table 1. Regression results of the determinants of aggregate supply, demand, prices and production costs. Each regression estimated separately with OLS

\begin{tabular}{|c|c|c|c|c|}
\hline & $H D_{t}$ & $H S_{t}$ & $D\left(P_{t}\right)$ & $D\left(P C_{t}\right)$ \\
\hline$P_{t}$ & $\begin{array}{l}-0.889 * * * \\
(0.180)\end{array}$ & & & \\
\hline$D\left(P_{t}\right)$ & $\begin{array}{l}7.456^{* * *} \\
(1.395)\end{array}$ & & $\begin{array}{l}0.823 * * * \\
(0.074)\end{array}$ & \\
\hline$D\left(P_{t-4}\right)$ & & $\begin{array}{l}9.300^{* * * *} \\
(1.841)\end{array}$ & & \\
\hline Intrate $_{t}$ & $\begin{array}{l}-8.733^{*} \\
(4.932)\end{array}$ & $\begin{array}{l}-16.558^{* * *} \\
(6.105)\end{array}$ & & \\
\hline Income $_{t}$ & $\begin{array}{l}0.780^{*} \\
(0.396)\end{array}$ & & & \\
\hline$D\left(P C_{t-1}\right)$ & & & & $\begin{array}{l}0.894 * * * \\
(0.087)\end{array}$ \\
\hline$D\left(P C_{t-4}\right)$ & & $\begin{array}{l}-13.160^{* *} \\
(2.102)\end{array}$ & & \\
\hline$D\left(H S_{t-1}\right)$ & & & & $\begin{array}{l}0.023^{* *} \\
(0.009)\end{array}$ \\
\hline$H S_{t-1}-H D_{t-1}$ & & & $\begin{array}{l}-0.033 * * * \\
(0.009)\end{array}$ & \\
\hline$C$ & $\begin{array}{l}9.828^{* * * *} \\
(2.222)\end{array}$ & $\begin{array}{l}9.062 * * * \\
(0.345)\end{array}$ & $\begin{array}{l}0.001 \\
(0.002)\end{array}$ & $\begin{array}{l}-0.001 \\
(0.001)\end{array}$ \\
\hline Adj. $R^{2}$ & 0.82 & 0.73 & 0.72 & 0.92 \\
\hline
\end{tabular}

Newey-West HAC standard errors in brackets, ***, **, * significant at the $1 \%, 5 \%$ or $10 \%$ level.

The four equations can be used to explain the dynamics in the housing market. We see that persistent low interest rates or increasing wages trigger a demand boom, that is followed by a price increase and supply boom. Due to the appreciation effect and also because with rising income relative house prices remain stable, the housing boom period can last for a quite long period. It will be stopped only by a shock, such as the sub-prime crisis in the USA, which made banks slow down the disbursement of loans.

The model helps to explain the price dynamics and the number of real estate transactions in the primary market. It suggests that the only way to achieve a market equilibrium and ensure small fluctuations around this point, is to stabilize and control demand, among others by slowing down the credit boom. Such a strong demand boom would probably not be possible in Poland, should only zloty denominated loans be granted. Moreover, the regulations related to the existence 
of the government-subsidized housing scheme sustained the demand (see: NBP, 2013). If, however, a programme aimed to support the rental housing market was introduced, the demand shock caused by rising incomes and low interest rates could be limited. Still, there is the secondary market and it is important to consider this market in the analysis of housing policy. We refer to Augustyniak et al. (2014) and NBP (2013b) for a detailed discussion on housing polices for the secondary housing market.

\section{Summary}

We present a relatively simple model that helps to understand the cyclical nature of the housing market. After calibrating the model to the primary housing market in Warsaw, we show how changes in interest rates affect the demand. Moreover, the model shows how demand shocks affect housing production and prices, and can lead to repeating housing cycles. It may be concluded that only the reduction in demand, for example, by prudential regulations limiting the availability of loanfinanced housing can help to smooth out the cycle in the primary housing market.

An important assumption of the model, motivated by empirical observations, is that the primary housing market is in constant dis-equilibrium. Delayed adjustments of supply to the continuously changing demand lead to permanent cycles. We wish to emphasize that the equilibrium assumption, on which most of the known housing models are based, gives erroneous results and misleading indications for decision makers. We believe that our model is useful for policy makers, central banks and regulators to analyse and understand the impact of various factors in the primary housing market.

Acknowledgements. We would like to thank an anonymous referee, the participants at the Warsaw International Economic Meeting 2012, the Christmas Financial Stability Seminar 2012 organized by the Bank of Slovakia and the Recent trends in the real estate market and its analysis workshop 2013 organized by the Narodowy Bank Polski for their comments. This paper appeared in its preliminary version in the NBP (2013) "Report on the situation in the Polish residential and commercial real estate market in 2012". The paper presents the personal opinions of the authors and does not necessarily reflect the official position of the Narodowy Bank Polski or the Warsaw School of Economics. 


\section{References}

Augustyniak, H., K. Gajewski, J. Łaszek and G. Żochowski (2012), Real estate development enterprises in the Polish market and issues related to its analysis, MPRA Paper 43347. Appeared also as Przedsiębiorstwo deweloperskie na rynku w Polsce oraz problemy jego analizy. Bezpieczny Bank, 2013, 4(53), 227-235.

Augustyniak, H., J. Łaszek, K. Olszewski and J. Waszczuk (2014), Modelling of cycles in the residential real estate markets - interactions between the primary and the secondary market and multiplier effects, Kwartalnik Nauk o Przedsiębiorstwie 2/2014 (31).

Bajari, P., P. Chan, D. Krueger and D. Miller (2013), A dynamic model of housing demand: estimation and policy implications, International Economic Review 54, 409-442.

Bracke, P. (2013), How Long Do Housing Cycles Last? A Duration Analysis for 19 OECD Countries., Journal of Housing Economics, 22(3), 213-230.

Burnham, J. B. (1972), Private Financial Institutions and the Residential Mortgage Cycle, with Particular Reference to the Savings and Loan Industry, In: Board of Governors of the Federal Reserve System, Ways To Moderate Fluctuations in Housing Construction.

Chang, C.-O. and C.W.R. Ward (1993), Forward pricing and the housing market: the pre-sales housing system in Taiwan, Journal of Property Research V 10, 217-227.

DiPasquale, D. and W. C. Wheaton (1992), The markets for Real Estate Assets and Space: A Conceptual Framework, Journal of the American Real Estate and Urban Economics Association, Vol. 20, 181-197.

DiPasquale, D. (1999), Why Don't We Know More About Housing Supply?, The Journal of Real Estate Finance and Economics, Vol. 18, 9-23.

Dunsky, R.M. and J.R. Follain (1997), The demand for mortgage debt and the income tax, Journal of Housing Research, Vol. 8, 155-199.

Epple, D., B. Gordon and H. Sieg (2010), A New Approach to Estimating the Production Function for Housing, The American Economic Review, Vol. 100(3), 905-924.

Fair, R. C. (1972), Disequilibrium in housing models, The Journal of Finance, 27(2), 207-221.

Hanau, A. (1928), Die Prognose der Schweinepreise (Forecasting the price of pork), Vierteljahreshefte zur Konjunkturforschung Sonderheft 7.

Henderson, J.V. and Y.M. Ioannides (1983), A Model of Housing Tenure Choice., The American Economic Review, Vol. 73(1), 98-113.

Lambertini, L., C. Mendicino and M. T. Punzi (2012), Expectations-Driven Cycles in the Housing Market, Bank of Finland Research Discussion Paper 2-2012.

Levin, E. J. and G. Pryce (2009), What Determines the Responsiveness of Housing Supply? The Role of Real Interest Rates and Cyclical Asymmetries., Housing Studies 24(6), 713-736. 
Lin, C. and S. Lin (1999), An Estimation of Elasticities of Consumption Demand and Investment Demand for Owner-Occupied Housing in Taiwan: A TwoPeriod Model, International Real Estate Review, Vol. 2, 110-125.

Łaszek, J. (2013), Housing and consumer theory, In: Report on the situation in the Polish residential and commercial real estate market in 2012, NBP.

Łaszek J. and K. Olszewski (2014). Zachowania firmy deweloperskiej na rynku mieszkań i zagregowana podaż. Mimeo.

Mayer, C. J., and C. T. Somerville (2000), Land use regulation and new construction. Regional Science and Urban Economics 30(6), 639-662.

Muth, R. (1960), The demand for non-farm housing, in A.C. Harberger, The demand for durable goods, The University of Chicago Press.

NBP (2011), Report on the situation in the Polish residential real estate market in $2010 \mathrm{r}$.

NBP (2012a), Report on the situation in the Polish residential real estate market in $2011 \mathrm{r}$.

NBP (2012b), Information on home prices and the situation in the residential and commercial real estate market in Poland in 2012 (Q1 and Q2).

NBP (2013a), Information on home prices and the situation in the residential and commercial real estate market in Poland in 2013 Q1.

NBP (2013b), Report on the situation in the Polish residential real estate market in $2012 \mathrm{r}$.

Phang, S. Y., K. H. Kim and S. Wachter (2010), Supply Elasticity of Housing, In: International Encyclopedia of Housing and Home, Elsevier and Science Direct.

Rubaszek, M. (2012), Mortgage down-payment and welfare in a life-cycle model, Bank and Credit, Vol. 43(4), 5-28.

Salzman, D.A.; Zwinkels, R.C.J. (2013), Behavioural Real Estate, Tinbergen Institute Discussion Paper, No. 13-088/IV/DSF58.

Sanchez, A. C. and A. Johansson (2011), The Price Responsiveness of Housing Supply in OECD Countries, OECD Economics Department Working Papers, No. 837.

Sommervoll, D. E., T.-A. Borgensen and T. Wennemo (2010), Endogenous housing market cycles, Journal of Banking \& Finance, Vol. 34, 557-567.

Stein, J. (1995), Prices and trading volume in the housing market: a model with downpayment constraints, Quarterly Journal of Economics, 110(2), 379-406.

Stover, M. E. (1986), The price elasticity of the supply of single-family detached urban housing, Journal of Urban Economics, 20(3), 331-340.

Steiner, E. (2010), Estimating a stock-flow model for the Swiss housing market, Swiss National Bank Working Papers 2010-08.

Topel, R. and S. Rosen (1988), Housing Investment in the United States, Journal of Political Economy, Vol. 96, 718-740.

Tse, R.Y.C., C.W. Ho and S. Ganesan (1999), Matching housing supply and demand: an empirical study of Hong Kong's market, Construction Management and Economicss Vol. 17, 625-633.

Wheaton, W. C. (1999), Real Estate "Cycles": Some Fundamentals, Real Estate Economics, Vol. 27,2, 209-230. 